Article

\title{
Optimal Extraction Study of Gastrodin-Type Components from Gastrodia Elata Tubers by Response Surface Design with Integrated Phytochemical and Bioactivity Evaluation
}

\author{
Minhui Hu, Hui Yan, Yuanyuan Fu, Yulan Jiang, Weifeng Yao, Sheng Yu, Li Zhang, Qinan Wu, \\ Anwei Ding and Mingqiu Shan *D \\ Jiangsu Collaborative Innovation Center of Chinese Medicinal Resources Industrialization, National and Local \\ Collaborative Engineering Center of Chinese Medicinal Resources Industrialization and Formulae Innovative \\ Medicine, Nanjing University of Chinese Medicine, Nanjing 210023, China; huminhui1353@163.com (M.H.); \\ glory-yan@163.com (H.Y.); 18251878790@163.com (Y.F.); jiangyulan226@126.com (Y.J.); \\ njweifengyao@163.com (W.Y.); yusheng1219@163.com (S.Y.); zhangliguanxiong@163.com (L.Z.); \\ qnwyjs@163.com (Q.W.); awding105@163.com (A.D.) \\ * Correspondence: shanmingqiu@njucm.edu.cn; Tel.: +86-025-85811519
}

Received: 9 January 2019; Accepted: 31 January 2019; Published: 2 February 2019

check for updates

\begin{abstract}
Gastrodia elata tuber (GET) is a popular traditional Chinese medicines (TCMs). In this study, response surface methodology (RSM) with a Box-Behnken design (BBD) was performed to optimize the extraction parameters of gastrodin-type components (gastrodin, gastrodigenin, parishin A, parishin B, parishin C and parishin E). Different from the conventional studies that merely focused on the contents of phytochemical, we gave consideration to both quantitative analysis of the above six components by HPLC and representative bioactivities of GET, including antioxidation and protection of human umbilical vein endothelial cells (HUVEC). Four independent variables (ethanol concentration, liquid-material ratio, soaking time and extraction time) were investigated with the integrated evaluation index of phytochemical contents. With the validation experiments, the optimal extraction parameters were as follows: ethanol concentration of $41 \%$, liquid-solid ratio of $28.58 \mathrm{~mL} / \mathrm{g}$, soaking time of $23.91 \mathrm{~h}$ and extraction time of $46.60 \mathrm{~min}$. Under the optimum conditions, the actual standardized comprehensive score was $1.8134 \pm 0.0110$, which was in accordance with the predicted score of 1.8100 . This firstly established method was proved to be feasible and reliable to optimize the extraction parameters of the bioactive components from GET. Furthermore, it provides some reference for the quality control and extraction optimization of TCMs.
\end{abstract}

Keywords: Gastrodia elata tuber (GET); Response surface methodology; Antioxidation; HUVEC; Gastrodin-type components

\section{Introduction}

Gastrodia elata $\mathrm{Bl}$. is a perennial parasitic herb belonging to the Orchidaceae family. The plant is commonly found in the mountainous areas of Eastern Asia, including China, Korea and Japan [1]. Gastrodia elata tuber (GET), also called "Tianma" in China, was firstly recorded as a premium traditional Chinese medicine (TCM) in "Shen Nong Ben Cao Jing." As a tonifying herbal medicine, GET has been used to extinguish wind to arrest convulsions, pacify and repress the liver yang, dispel wind and unblock the collaterals in clinic for thousands of years [2]. In modern pharmacological studies, GET has antioxidant, anti-angiogenic, neuroprotective, antidepressant, anxiolytic and sedative activities [3-9]. GET is also a quite favorite food that could improve body function and enhance immunity which 
frequently appears in the soup or porridge with chicken, pigeon, duck, fish head and so forth, in East Asia. Because of its high edible and health value, this herbal medicine is listed as one of the functional foods approved by the Ministry of Health in China [10,11].

For gastrodin (GD) is one of the predominant bioactive compounds in GET and gastrodigenin (GG, 4-hydroxybenzyl alcohol) due to its aglycone, which can exert specific pharmacological activities [12-15], it is listed as one of the quality evaluation indicators of GET in the Chinese Pharmacopoeia. Therefore, most studies with respect to the processing and extraction of GET only focused on these two chemical evaluation indexes [16-19]. However, there are some other ester derivatives of GD(s) in GET when combining with a citric acid, such as parishin A (PA), parishin $\mathrm{B}(\mathrm{PB})$, parishin $\mathrm{C}(\mathrm{PC})$ and parishin $\mathrm{E}$ (PE). The contents of these partial compounds were even higher than that of GD [20,21]. They also exhibited some promising pharmacological activities, including long-term potentiation protective, antiaging and antipsychotic effects [22-25], which were similar to that of GD, GG and GET. The cases might be explained by some researches that gastrodin and gastrodigenin are the major metabolites of the above parishin derivatives [26,27]. In this paper, considering their similar chemical structures (see Figure 1), these six components are grouped into gastrodin-type components, which were recognized as the material basis of GET.

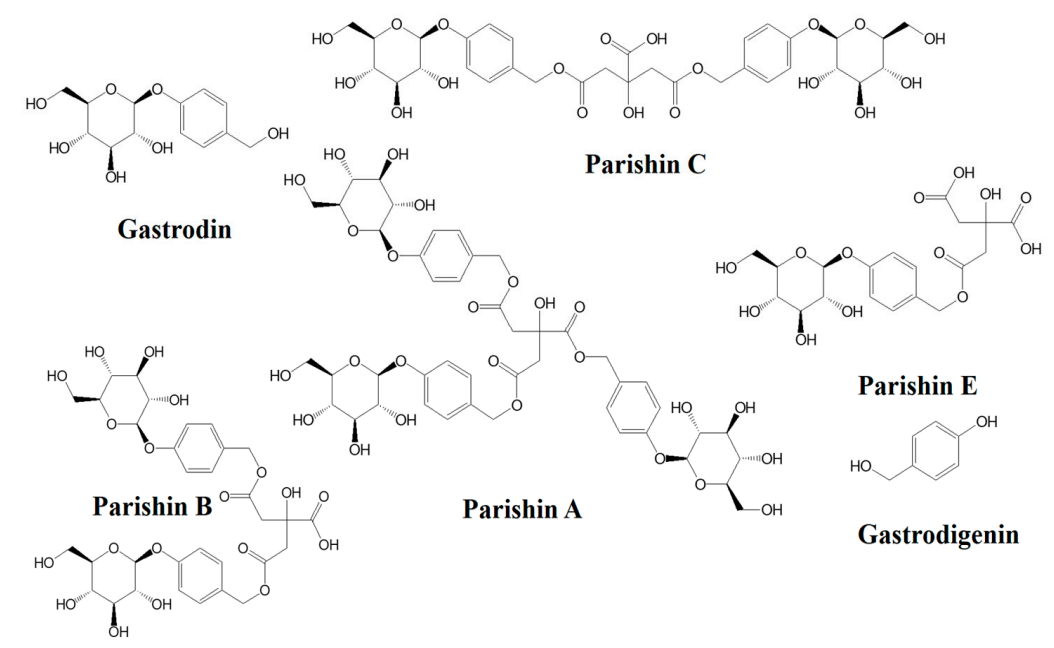

Figure 1. Chemical structures of the gastrodin-type components.

In addition, as we know, the curative effect is the straightforward index for quality evaluation of herbal medicine. GET was reported as one of the earliest and most fundamental medicinal foods to treat vascular diseases including hypertension and atherosclerosis. The protection of this phytomedicine on human umbilical vein endothelial cells (HUVEC) involved in these bioactivities [28,29]. On the other hand, with many polyphenols including the gastrodin-type components mentioned above, GET exerted predominant antioxidant activity, which also played a crucial role in its efficacies and was related to many pharmacological bioactivities, such as protection on liver and kidney jury, antiaging, reducing cerebral ischemia/reperfusion injury, antihypertension, neuroprotection [30-36]. Hence, HUVEC protective and antioxidant properties could also be utilized to reflect GET quality.

With multiple quadratic regression equation, response surface methodology (RSM) is a novel statistical approach to solve multi-variable problems. RSM has been widely used to find out the optimum parameters of different kinds of process in TCM, such as extraction, processing and purification [37-42]. However, in almost all the relative studies, the contents of major compounds have been paid much attention, neglecting other critical bioactivities. In this study, taking both phytochemical yields and bioactivities as integrated evaluation indicators, we aim to optimize the extraction parameters of the gastrodin-type components from GET and to provide some reference for natural products extraction from other TCMs. 


\section{Results}

\subsection{Method Validation}

The linearity, regression equation and linear ranges of six gastrodin-type components were investigated with standard solutions of different concentrations. The results in Table 1 showed a good linearity between the measured concentrations and their peak areas of each analyte in the linear range $(\mathrm{R}>0.9992)$. Limit of Detection (LOD) and Limit of Quantity (LOQ) values for the analytes were also listed in Table 1.

Table 1. The regression equations, LODs and LOQs of six gastrodin-type components.

\begin{tabular}{cccccc}
\hline Analyte & Regression Equation & $\begin{array}{c}\text { Linear Range } \\
(\mu \mathbf{g} / \mathbf{m L})\end{array}$ & $\mathbf{R}^{\mathbf{2}}$ & LOD $(\mu \mathrm{g} / \mathbf{m L})$ & $\mathbf{L O Q}(\mu \mathrm{g} / \mathbf{m L})$ \\
\hline Gastrodin (GD) & $Y=1781.62 X+1448.30$ & $5.21-166.64$ & 0.9997 & 2.19 & 6.95 \\
Gastrodigenin (GG) & $Y=7335.04 X-1097.67$ & $2.15-68.68$ & 0.9999 & 1.38 & 4.91 \\
Parishin E (PE) & $Y=1265.20 X-1840.13$ & $9.75-312.00$ & 0.9999 & 0.47 & 1.72 \\
Parishin B (PB) & $Y=1842.78 X-6412.23$ & $8.42-269.28$ & 0.9993 & 3.76 & 13.80 \\
Parishin C (PC) & $Y=764.82 X-70.51$ & $5.04-161.36$ & 0.9999 & 2.81 & 6.43 \\
Parishin A (PA) & $Y=956.37 X-6952.21$ & $23.83-762.56$ & 0.9997 & 3.92 & 10.60 \\
\hline
\end{tabular}

Precision, repeatability and stability were evaluated by RSD values in Table 2 . The RSD of the precision values of six gastrodin-type components were less than $3.27 \%$. The extraction recovery rates of the analytes ranged from $96.99 \%$ to $101.72 \%$, with the RSD values lower than $2.32 \%$. RSD values for the stability and the repeatability were less than $2.45 \%$ and $2.75 \%$, respectively. All results indicated that the developed method is stable, accurate and repeatable. This established HPLC method could be applied to simultaneous determination of GD, GG, PA, PB, PC and PE in GET samples. Representative HPLC chromatograms of standard solution and sample solution were shown in Figure 2.

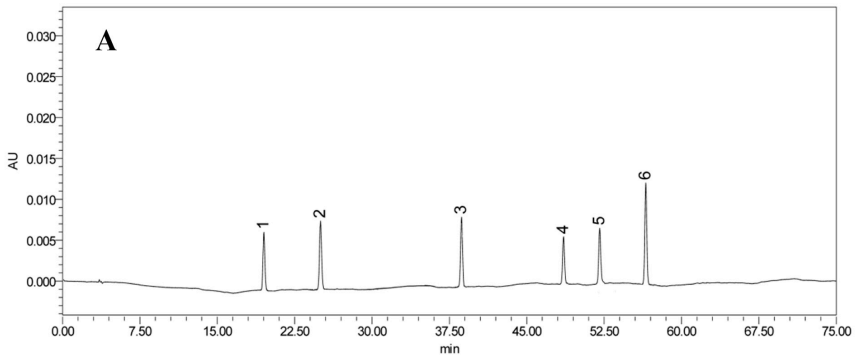

1. Gastrodin (GD)

2. Gastrodigenin (GG)

3. Parishin E (PE)

4. Parishin $B(P B)$

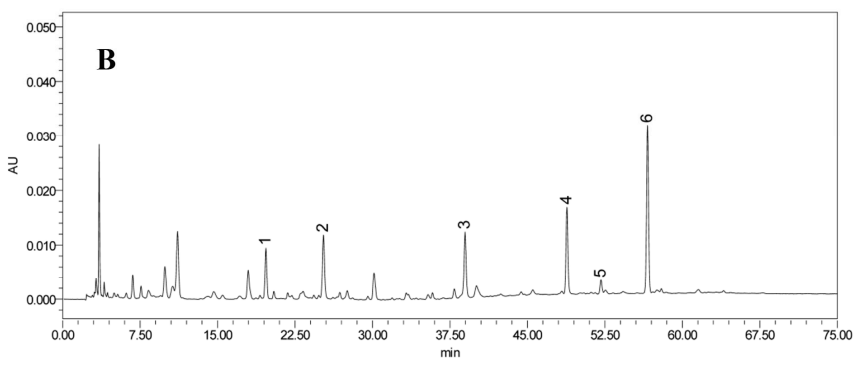

5. Parishin $C(P C)$

6. Parishin A (PA)

Figure 2. HPLC chromatograms of gastrodin-type components in (A) standard solution and (B) sample solution. 
Table 2. RSD of precision, stability, repeatability and accuracy for determination of six gastrodin-type components.

\begin{tabular}{ccccccc}
\hline \multirow{2}{*}{ Analyte } & \multicolumn{2}{c}{ Precision } & & \multirow{2}{c}{ Repeatability } \\
\cline { 2 - 3 } & $\begin{array}{c}\text { Intra-Day RSD } \\
\text { (\%) }\end{array}$ & $\begin{array}{c}\text { Inter-Day RSD } \\
\mathbf{( \% )}\end{array}$ & Stability RSD (\%) & \multicolumn{2}{c}{ Recovery } \\
\hline GD & 2.42 & 2.89 & 2.01 & & Mean (\%) & RSD (\%) \\
GG & 1.06 & 2.06 & 1.22 & 1.61 & 98.15 & 1.60 \\
PE & 1.22 & 3.27 & 1.03 & 1.21 & 98.09 & 2.32 \\
PB & 2.65 & 2.80 & 1.89 & 2.75 & 101.72 & 2.14 \\
PC & 2.15 & 1.95 & 2.45 & 2.03 & 96.99 & 0.92 \\
PA & 2.26 & 3.04 & 2.30 & 2.23 & 99.57 & 2.25 \\
\hline
\end{tabular}

\subsection{Optimization of Extraction Procedure}

The single-factor study was conducted to evaluate the effect of each parameter on the extraction rate and to determine the level range for BBD. With normalized contents of the target components, the effects of the four parameters on the yields of six phytochemicals in GET $\left(Y_{1}\right)$ were shown in Figure 3. From the figure, the three levels of each parameter were selected: $20 \%, 40 \%, 60 \%$ for ethanol concentration; 16, 28, 40 for liquid-solid ratio; $30 \mathrm{~min}, 45 \mathrm{~min}, 60 \mathrm{~min}$ for extraction time; $12 \mathrm{~h}, 24 \mathrm{~h}$, $36 \mathrm{~h}$ for soaking time.

A
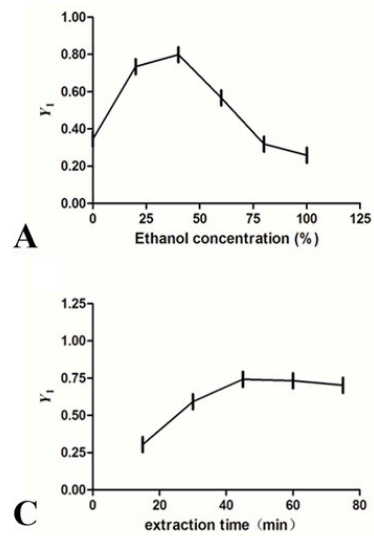

B
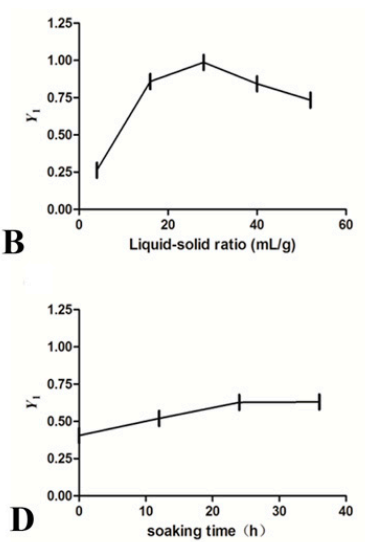

Figure 3. Effect of different extraction parameters (A: ethanol concentration, \%; B: liquid-solid ratio, $\mathrm{mL} / \mathrm{g}$; C: extraction time, min; D: soaking time, h) on $Y_{1}$.

\subsection{Optimization of DPPH Assay}

In DPPH free radical scavenging assay, the reaction time and the concentration of DPPH solution were the fundamental parameters. The single-factor study was performed to assess the effect of these two factors on DPPH scavenging (see Figure 4). In terms of DPPH free radical scavenging rate, $50 \%$ was more rational and acceptable in condition optimization. Based on this point, the optimal DPPH concentration and reaction time were $75 \mu \mathrm{g} / \mathrm{mL}$ and $40 \mathrm{~min}$, respectively.
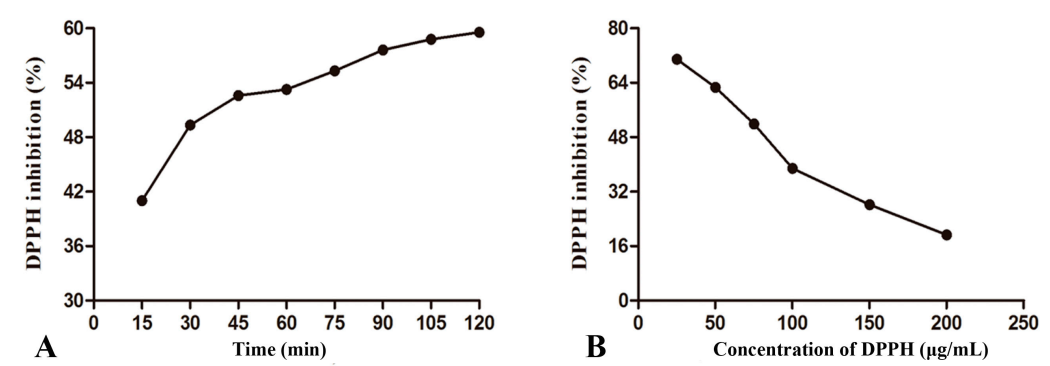

Figure 4. The single-factor study of DPPH assay (A: reaction time B: DPPH concentration). 


\subsection{Optimization of the Procedure}

\subsubsection{The Statistical Analysis and Model Fitting}

BBD experiment with four factors and three levels was carried out to optimize the four independent factors on the extraction of GET. Table 3 showed the design and the results of the dependent variables while Table 4 listed the comprehensive scores of all 29 runs. By the multivariate regression analysis, the fitted full quadratic models given by equation were obtained for the comprehensive evaluation as follows:

$Y=1.80+0.016 X_{1}+0.13 X_{2}+0.094 X_{3}-0.021 X_{4}-0.11 X_{1} X_{2}+0.13 X_{1} X_{3}+0.10 X_{1} X_{4}-0.20 X_{2} X_{3}+$ $0.25 X_{2} X_{4}+0.042 X_{3} X_{4}-0.47 X_{1}^{2}-1.11 X_{2}^{2}-0.42 X_{3}^{2}-0.18 X_{4}^{2}$

Table 3. The experimental design and results with four independent variables.

\begin{tabular}{|c|c|c|c|c|c|c|c|c|c|c|c|c|}
\hline No. & $X_{1}$ & $X_{2}$ & $X_{3}$ & $X_{4}$ & $\begin{array}{l}\text { GD } \\
(\mathrm{mg} / \mathrm{g})\end{array}$ & $\begin{array}{c}\text { GG } \\
(\mathrm{mg} / \mathrm{g})\end{array}$ & $\begin{array}{c}\mathrm{PE} \\
(\mathrm{mg} / \mathrm{g})\end{array}$ & $\begin{array}{c}\text { PB } \\
(\mathrm{mg} / \mathrm{g})\end{array}$ & $\begin{array}{c}\text { PC } \\
(\mathrm{mg} / \mathrm{g})\end{array}$ & $\begin{array}{c}\mathrm{PA} \\
(\mathrm{mg} / \mathrm{g})\end{array}$ & $\begin{array}{l}\mathrm{IC}_{50} \\
(\mathrm{mg} / \mathrm{mL}\end{array}$ & $\begin{array}{l}\mathrm{S}_{\mathrm{MTT}} \\
\text { L) }(\%)\end{array}$ \\
\hline 1 & 0 & 1 & 0 & 1 & 1.88 & 0.57 & 2.79 & 3.85 & 1.43 & 13.75 & 37.80 & 29.34 \\
\hline 2 & -1 & 0 & 1 & 0 & 1.09 & 0.43 & 2.90 & 2.20 & 0.81 & 7.00 & 26.05 & 38.65 \\
\hline 3 & 0 & 0 & 1 & 1 & 1.74 & 0.63 & 4.66 & 3.65 & 1.39 & 13.59 & 28.11 & 30.87 \\
\hline 4 & 0 & 0 & -1 & -1 & 1.91 & 0.61 & 5.05 & 3.98 & 1.47 & 14.32 & 32.68 & 34.22 \\
\hline 5 & -1 & 0 & 0 & -1 & 1.64 & 0.65 & 4.30 & 3.27 & 1.20 & 10.79 & 29.92 & 35.75 \\
\hline 6 & -1 & 0 & 0 & 1 & 1.57 & 0.23 & 4.26 & 3.30 & 1.26 & 9.88 & 28.27 & 33.28 \\
\hline 7 & 0 & 0 & 1 & -1 & 1.83 & 0.65 & 4.87 & 3.83 & 1.45 & 14.02 & 28.93 & 28.52 \\
\hline 8 & 0 & 0 & -1 & 1 & 1.73 & 0.62 & 4.64 & 3.68 & 1.34 & 13.4 & 30.31 & 32.74 \\
\hline 9 & 1 & 0 & 0 & -1 & 1.73 & 0.63 & 3.17 & 2.84 & 0.80 & 10.71 & 29.61 & 36.81 \\
\hline 10 & 0 & 0 & 0 & 0 & 1.84 & 0.65 & 4.93 & 3.86 & 1.43 & 14.27 & 22.07 & 37.63 \\
\hline 11 & 1 & -1 & 0 & 0 & 1.64 & 0.61 & 2.73 & 2.89 & 0.83 & 11.12 & 34.26 & 22.15 \\
\hline 12 & 0 & 1 & -1 & 0 & 1.85 & 0.65 & 4.95 & 3.96 & 1.45 & 14.29 & 36.24 & 23.58 \\
\hline 13 & 1 & 0 & -1 & 0 & 1.53 & 0.12 & 2.81 & 2.67 & 0.74 & 10.14 & 28.97 & 28.30 \\
\hline 14 & 1 & 0 & 0 & 1 & 1.74 & 0.62 & 3.66 & 3.44 & 1.06 & 12.47 & 26.3 & 35.37 \\
\hline 15 & -1 & 1 & 0 & 0 & 1.60 & 0.58 & 4.18 & 3.16 & 1.17 & 10.57 & 31.76 & 22.81 \\
\hline 16 & 0 & 0 & 0 & 0 & 1.94 & 0.61 & 5.01 & 3.88 & 1.48 & 14.39 & 21.87 & 38.62 \\
\hline 17 & 0 & -1 & 0 & -1 & 1.76 & 0.62 & 4.69 & 3.76 & 1.35 & 13.61 & 34.55 & 29.55 \\
\hline 18 & 0 & -1 & 1 & 0 & 1.55 & 0.55 & 4.13 & 3.26 & 1.21 & 12.18 & 39.91 & 28.23 \\
\hline 19 & -1 & 0 & -1 & 0 & 1.44 & 0.55 & 3.90 & 3.08 & 1.13 & 10.37 & 27.04 & 29.91 \\
\hline 20 & 0 & 0 & 0 & 0 & 1.86 & 0.67 & 4.96 & 3.83 & 1.42 & 14.26 & 21.23 & 38.28 \\
\hline 21 & 0 & 0 & 0 & 0 & 1.69 & 0.62 & 4.57 & 3.59 & 1.30 & 13.14 & 22.08 & 32.14 \\
\hline 22 & 0 & 1 & 0 & -1 & 1.62 & 0.49 & 4.24 & 3.45 & 1.26 & 11.85 & 38.77 & 24.55 \\
\hline 23 & 0 & 0 & 0 & 0 & 1.86 & 0.59 & 4.84 & 3.76 & 1.40 & 13.92 & 21.58 & 36.16 \\
\hline 24 & 0 & -1 & -1 & 0 & 1.62 & 0.59 & 4.27 & 3.38 & 1.22 & 12.66 & 44.65 & 18.13 \\
\hline 25 & 0 & -1 & 0 & 1 & 1.71 & 0.63 & 4.55 & 3.62 & 1.31 & 13.21 & 42.43 & 24.20 \\
\hline 26 & -1 & -1 & 0 & 0 & 0.81 & 0.32 & 2.16 & 1.67 & 0.60 & 5.53 & 35.93 & 25.01 \\
\hline 27 & 0 & 1 & 1 & 0 & 1.80 & 0.65 & 4.86 & 3.90 & 1.35 & 14.04 & 41.54 & 25.66 \\
\hline 28 & 1 & 0 & 1 & 0 & 1.73 & 0.55 & 3.18 & 3.12 & 0.86 & 11.53 & 29.56 & 36.61 \\
\hline 29 & 1 & 1 & 0 & 0 & 1.64 & 0.64 & 3.37 & 3.10 & 0.93 & 11.24 & 33.75 & 24.90 \\
\hline
\end{tabular}

By ANOVA and regression analysis (R2) method to predict the reliability of the model, the analysis of variance, goodness-of-fit and the adequacy of the regression model were listed in Table 5. The model p-value was less than 0.0001, indicating that the model was highly significant, acceptable and suitable for this experiment. In this model, the coefficient, the adjusted coefficient and the predicted coefficient were $0.9463,0.8925$ and 0.7511 , respectively, indicating that $94.63 \%$ of the response value changes could be explained by the model. These results confirmed that the model could be adequate to explain the relationship between the response and the independent variables. The adequacy of the fit was evaluated by the lack of fit. The F-value of 1.09 and $p$-value of 0.5101 manifested that the lack of fit was not significant to the pure error and confirmed the suitability of regression model. Additionally, adequate precision in this study was 13.777 , by calculating the ratio of the predicted values range at the design points to the average prediction error. The results proved the adequate model was discriminated. 
Table 4. Box-Behnken design for independent variables and observed responses.

\begin{tabular}{cccccccccc}
\hline No. & $\boldsymbol{Y}_{\mathbf{1}}$ & $\boldsymbol{Y}_{\mathbf{2}}$ & $\boldsymbol{Y}_{\mathbf{3}}$ & $\boldsymbol{Y}$ & $\mathbf{N o}$ & $\boldsymbol{Y}_{\mathbf{1}}$ & $\boldsymbol{Y}_{\mathbf{2}}$ & $\boldsymbol{Y}_{\mathbf{3}}$ & $\boldsymbol{Y}$ \\
\hline 1 & 0.7996 & 0.7075 & 0.5466 & 0.6387 & 16 & 0.9723 & 0.0273 & 0.9986 & 1.9436 \\
2 & 0.2836 & 0.2058 & 1.0000 & 1.0778 & 17 & 0.8824 & 0.5687 & 0.5568 & 0.8704 \\
3 & 0.8800 & 0.2938 & 0.6208 & 1.2070 & 18 & 0.7084 & 0.7976 & 0.4924 & 0.4032 \\
4 & 0.9742 & 0.4889 & 0.7844 & 1.2696 & 19 & 0.6167 & 0.2481 & 0.5741 & 0.9427 \\
5 & 0.7345 & 0.3711 & 0.8586 & 1.2220 & 20 & 0.9584 & 0.0000 & 0.9821 & 1.9405 \\
6 & 0.5910 & 0.3006 & 0.7386 & 1.0290 & 21 & 0.8346 & 0.0363 & 0.6831 & 1.4813 \\
7 & 0.9439 & 0.3288 & 0.5065 & 1.1216 & 22 & 0.7239 & 0.7489 & 0.3131 & 0.2880 \\
8 & 0.8634 & 0.3877 & 0.7119 & 1.1876 & 23 & 0.9120 & 0.0149 & 0.8786 & 1.7756 \\
9 & 0.5682 & 0.3578 & 0.9103 & 1.1207 & 24 & 0.7585 & 1.0000 & 0.0000 & -0.2415 \\
10 & 0.9519 & 0.0359 & 0.9505 & 1.8666 & 25 & 0.8448 & 0.9052 & 0.2960 & 0.2356 \\
11 & 0.5405 & 0.5564 & 0.1959 & 0.1801 & 26 & 0.0606 & 0.6277 & 0.3354 & -0.2317 \\
12 & 0.9659 & 0.6409 & 0.2658 & 0.5907 & 27 & 0.9254 & 0.8672 & 0.3669 & 0.4251 \\
13 & 0.3291 & 0.3305 & 0.4955 & 0.4941 & 28 & 0.5915 & 0.3557 & 0.9009 & 1.1368 \\
14 & 0.7206 & 0.2165 & 0.8403 & 1.3444 & 29 & 0.6229 & 0.5346 & 0.3300 & 0.4183 \\
15 & 0.6827 & 0.4496 & 0.2281 & 0.4612 & & & & & \\
\hline
\end{tabular}

Table 5. ANOVA for response surface quadratic model analysis of variance.

\begin{tabular}{|c|c|c|c|c|c|}
\hline Source & Sum of Squares & Degree of Freedom & Mean Square & F-Value & $p$-Value \\
\hline Model & 9.6300 & 14 & 0.6900 & 17.61 & $<0.0001$ \\
\hline$X_{1}$ & 0.0031 & 1 & 0.0031 & 0.08 & 0.7817 \\
\hline$X_{2}$ & 0.2100 & 1 & 0.2100 & 5.5 & 0.0342 \\
\hline$X_{3}$ & 0.1100 & 1 & 0.1100 & 2.72 & 0.1215 \\
\hline$X_{4}$ & 0.0052 & 1 & 0.0052 & 0.13 & 0.7204 \\
\hline$X_{1} X_{2}$ & 0.0520 & 1 & 0.0520 & 1.32 & 0.2692 \\
\hline$X_{1} X_{3}$ & 0.0640 & 1 & 0.0640 & 1.65 & 0.2199 \\
\hline$X_{1} X_{4}$ & 0.0430 & 1 & 0.0430 & 1.11 & 0.3096 \\
\hline$X_{2} X_{3}$ & 0.1600 & 1 & 0.1600 & 4.2 & 0.0595 \\
\hline$X_{2} X_{4}$ & 0.2400 & 1 & 0.2400 & 6.22 & 0.0258 \\
\hline$X_{3} X_{4}$ & 0.0070 & 1 & 0.0070 & 0.18 & 0.6783 \\
\hline$X_{1}^{2}$ & 1.4200 & 1 & 1.4200 & 36.33 & $<0.0001$ \\
\hline$X_{2}{ }^{2}$ & 8.0300 & 1 & 8.0300 & 205.52 & $<0.0001$ \\
\hline$X_{3}^{2}$ & 1.1200 & 1 & 1.1200 & 28.64 & 0.0001 \\
\hline$X_{4}^{2}$ & 0.2000 & 1 & 0.2000 & 5.1 & 0.0404 \\
\hline Residual & 0.5500 & 14 & 0.0390 & & \\
\hline Lack of Fit & 0.4000 & 10 & 0.0400 & 1.09 & 0.5101 \\
\hline Pure Error & 0.1500 & 4 & 0.0370 & & \\
\hline Cor Total & 10.1700 & 28 & & & \\
\hline$R^{2}$ & 0.9463 & & & & \\
\hline Adjusted $R^{2}$ & 0.8925 & & & & \\
\hline Predicted $\mathrm{R}^{2}$ & 0.7511 & & & & \\
\hline $\begin{array}{l}\text { Adequate } \\
\text { precision }\end{array}$ & 13.777 & & & & \\
\hline
\end{tabular}

As shown in Table 5, $p$-value of each model term indicated that the quadratic terms of $X_{1}{ }^{2}, X_{2}{ }^{2}$ and $X_{3}{ }^{2}$ were found to have the largest effects on the model $(p<0.001)$. The quadratic terms of $X_{4}^{2}$ and $X_{2} X_{4}$ were also significant terms $(p<0.05)$ with the linear term of $X_{2}$. However, the other terms' effects were not significant $(p>0.05)$.

\subsubsection{Analysis of the Response Surface}

The three-dimension response surface plots drawn by BBD were shown in Figure 5, which described the regression equation through a clear and intuitive approach and revealed the mutual effects of parameters on the comprehensive score and their reciprocal interactions. In each figure, the simultaneous effects of two factors on the response were shown by the plots and the other two factors were maintained at zero level. 

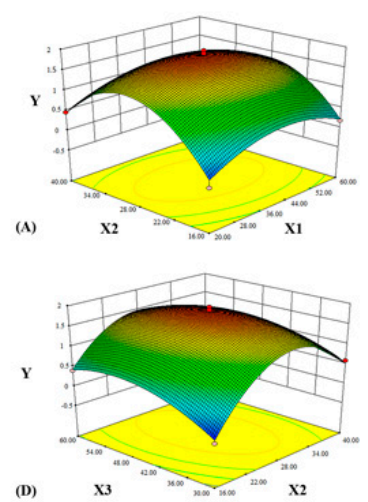
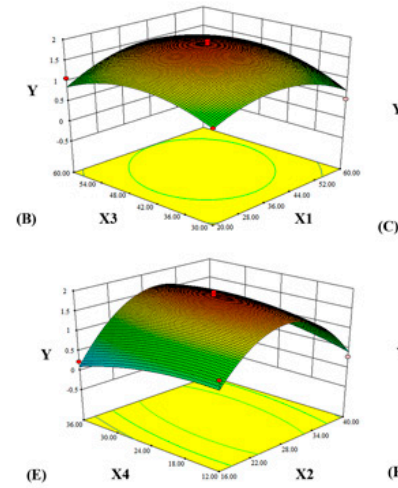

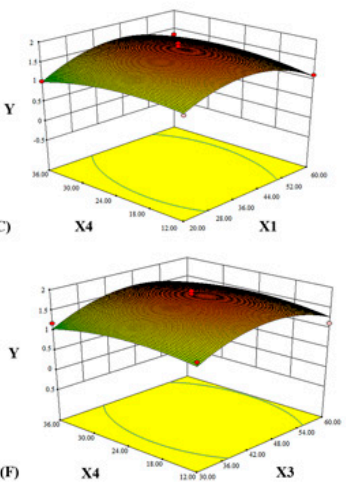

Figure 5. Response surface showing the interaction effects of different parameters $\left(A: X_{1}\right.$ and $X_{2} ; \mathbf{B}: X_{1}$ and $X_{3} ; \mathrm{C}: X_{1}$ and $X_{4} ; \mathrm{D}: X_{2}$ and $X_{3} ; \mathbf{E}: X_{2}$ and $X_{4} ; \mathrm{F}: X_{3}$ and $\left.X_{4}\right)$ on the response $Y\left(X_{1}\right.$ : ethanol concentration, $\% ; X_{2}$ : liquid-solid ratio, $\mathrm{mL} / \mathrm{g} ; \mathrm{X}_{3}$ : extraction time, $\mathrm{min} ; \mathrm{X}_{4}$ : soaking time, $\mathrm{h}$ ).

Figure 5A represented the effects of liquid-solid ratio and ethanol concentration on the $Y$ value. Both liquid-solid ratio and ethanol concentration had the positive effects on $Y$. It can be seen that $Y$ mainly replied upon liquid-solid ratio that led to a curvilinear increase until $29 \mathrm{~mL} / \mathrm{g}$, then decreased. $Y$ increased slightly when the ethanol concentration was from $20 \%$ to $41 \%$ and the concentration curve indicated that $41 \%$ was able to achieve the greatest increase. Figure $5 \mathrm{~B}$ described the interaction effect of ethanol concentration and extraction time on $Y$. The effect of extraction time was essentially equivalent to the ethanol concentration. As the ethanol concentration was close to $41 \%, Y$ value increased greatly while the range of extraction time was from $30 \mathrm{~min}$ to $47 \mathrm{~min}$. It can be seen in Figure $5 \mathrm{C}$, the soaking time exhibited the weaker effect while ethanol concentration expressed a great effect on $Y$. As the soaking time prolonged from 0 to $24 \mathrm{~h}$, the $Y$ value increased. Therefore, $Y$ was required to achieve a large value with the increasing of ethanol concentration, especially when the soaking time was close to 24 hours. The effects of extraction time and liquid-solid ratio on the yield of $Y$ were shown in Figure 5D. It was obvious that the shorter extraction time resulted in lower $Y$ value. While the liquid-solid ratio reached to a middle level, the $Y$ value increased with a rise of extraction time. According to Figure 5E, it can be seen that the interaction between soaking time and liquid-solid ratio had significant effect on the $Y$ value. It showed that the result was basically consistent with the preliminary experimental result and could prove the accurate value of the parameter. The effects of extraction time and soaking time on the $Y$ values could be seen in Figure 5F. Apparently, the shorter the soaking time presented the lower the $Y$ value. In general, the soaking time had weak effect on the $Y$ value, otherwise the liquid-solid ratio had the most significant effect.

\subsubsection{Verification of Predictive Model}

By Design-Expert 8.0 software, the optimum conditions for extraction of the gastrodin-type components were obtained and presented as follows: the ethanol concentration of $41 \%$, the liquid-solid ratio of $28.58 \mathrm{~mL} / \mathrm{g}$, the soaking time of $23.91 \mathrm{~h}$ and the extraction time of $46.60 \mathrm{~min}$. Under the conditions, the predicted comprehensive score $(Y)$ was 1.8100 . To verify the availability of the model equation, triplicate confirmatory experiments were carried out, which resulted in GD content of $1.95 \pm 0.01 \mathrm{mg} / \mathrm{g}$, GG content of $0.69 \pm 0.02 \mathrm{mg} / \mathrm{g}$, PA content of $14.02 \pm 0.05 \mathrm{mg} / \mathrm{g}$, PB content of $5.00 \pm 0.13 \mathrm{mg} / \mathrm{g}$, PC content of $1.40 \pm 0.03 \mathrm{mg} / \mathrm{g}$, PE content of $4.31 \pm 0.03 \mathrm{mg} / \mathrm{g}$, DPPH $\mathrm{IC}_{50}$ of $24.41 \pm 0.33 \mathrm{mg} / \mathrm{mL}$ and HUVEC damage repair rate of $37.27 \pm 0.15 \%$. The results of verification of predictive model were listed in Table 6 . The experimental comprehensive score $(Y)$ was $1.8134 \pm 0.0110$, with no significance to the predicted one. Therefore, the model based on integrated chemical and pharmacological evaluation was suitable for the optimization of extraction process of GET. The confirmatory experiment proved that the model was adequate for the extraction process. 
Table 6. The results of verification of predictive model.

\begin{tabular}{ccccccccc}
\hline No. & $\begin{array}{c}\text { GD } \\
(\mathbf{m g} / \mathbf{g})\end{array}$ & $\begin{array}{c}\text { GG } \\
(\mathbf{m g} / \mathbf{g})\end{array}$ & $\begin{array}{c}\text { PE } \\
(\mathbf{m g} / \mathbf{g})\end{array}$ & $\begin{array}{c}\text { PB } \\
(\mathbf{m g} / \mathbf{g})\end{array}$ & $\begin{array}{c}\text { PC } \\
(\mathbf{m g} / \mathbf{g})\end{array}$ & $\begin{array}{c}\text { PA } \\
(\mathbf{m g} / \mathbf{g})\end{array}$ & $\begin{array}{c}\mathrm{IC}_{50} \\
(\mathbf{m g} / \mathbf{m L})\end{array}$ & $\begin{array}{c}\mathrm{S}_{\mathrm{MTT}} \\
(\mathbf{\%})\end{array}$ \\
\hline 1 & 1.946 & 0.676 & 4.335 & 4.844 & 1.428 & 14.050 & 24.50 & 37.44 \\
2 & 1.946 & 0.707 & 4.310 & 5.070 & 1.370 & 13.958 & 24.04 & 37.15 \\
3 & 1.945 & 0.688 & 4.277 & 5.082 & 1.416 & 14.054 & 24.68 & 37.21 \\
\hline
\end{tabular}

\section{Materials and Methods}

\subsection{Chemicals and Materials}

GETs were obtained from Liuan City, Anhui Province China and then identified by Qinan Wu in Nanjing University of Chinese Medicine (NJUCM). The voucher specimen was stored at the herbarium of NJUCM. GD (95.4\% purity) and GG (98.5\% purity) were purchased from National Institute for the Control of Pharmaceutical and Biological Products. PA, PB, PC and PE were purchased from Nanjing Jinyibai Biotechnology Co., Ltd. (Nanjing, China), whose purities were more than 98\% by HPLC. 1,1-diphenyl-2-picrylhydrazyl (DPPH) was purchased from TCI Chemical Industry Development (Shanghai, China). HUVEC were purchased from Shanghai Baili Biotechnology Co., Ltd. (Shanghai, China). 3-(4,5-Dimethylthiazol-2-yl)-2,5-diphenyltetrazolium bromide (MTT) was purchased from Shanghai Aladdin Biotechnology Co., Ltd. (Shanghai, China). HPLC-grade methanol was provided by Merck Serono Co., Ltd. (Darmstadt, Germany). Ultrapure water was obtained by Milli-Q super purification system (Millipore, Bedford, MA, USA). All other chemicals were of analytical grade.

\subsection{Preparation of Standard Solutions}

Mixed standard stock solution containing GD, GG, PA, PB, PC and PE was prepared in 2\% methanol with the final concentrations of $20.8 \mu \mathrm{g} / \mathrm{mL}, 17.2 \mu \mathrm{g} / \mathrm{mL}, 19.5 \mu \mathrm{g} / \mathrm{mL}, 16.8 \mu \mathrm{g} / \mathrm{mL}$, $20.2 \mu \mathrm{g} / \mathrm{mL}$ and $23.8 \mu \mathrm{g} / \mathrm{mL}$, respectively. This solution was diluted with $2 \%$ methanol to appropriate concentrations for linearity test. All the standard solutions were stored in a refrigerator at $4{ }^{\circ} \mathrm{C}$ before use.

\subsection{Sample Preparation}

All the GET samples were powdered and passed through an 80 mesh screen. $0.5 \mathrm{~g}$ of each sample was accurately weighed and mixed with aqueous ethanol of different concentrations and different volumes at room temperature. The solutions were soaked for different time ranging from 12 to 36 hours and then extracted by ultrasonic method for 30 to 60 minutes. After extraction, each solution was centrifuged at $4000 \mathrm{rpm}$ for 5 minutes and the supernatant was evaporated to dryness. Then the residual was dissolved with $2 \%$ methanol in a $10 \mathrm{~mL}$ volumetric flask. After centrifugation at $12,000 \mathrm{rpm}$ and filtration to remove the residue by using filter paper, the sample solution was stored in a refrigerator at $4{ }^{\circ} \mathrm{C}$. Extraction details of each sample are described in Table 7 .

Table 7. Variables and experimental design levels for RSM.

\begin{tabular}{ccccc}
\hline \multirow{2}{*}{ Independent Variables } & Coded Symbols & \multicolumn{3}{c}{ Levels } \\
\cline { 3 - 5 } & & $\mathbf{- 1}$ & $\mathbf{0}$ & $\mathbf{1}$ \\
\hline Ethanol concentration $(\%)$ & $X_{1}$ & 20 & 40 & 60 \\
Liquid-solid ratio (mL/g) & $X_{2}$ & $16: 1$ & $28: 1$ & $40: 1$ \\
Extraction time (min) & $X_{3}$ & 30 & 45 & 60 \\
Soaking time (h) & $X_{4}$ & 12 & 24 & 36 \\
\hline
\end{tabular}




\subsection{Determination of the Gastrodin-Type Components}

\subsubsection{Chromatographic Conditions}

A Waters e2695 HPLC system (Waters Corporation, Milford, MA, USA) with a Waters Symmetry C18 column $(4.6 \mathrm{~mm} \times 250 \mathrm{~mm}, 5 \mu \mathrm{m})$ was used for separation. Mobile phase was composed of $0.04 \mathrm{M}$ formic acid (A) and methanol (B) with gradient elution as follows: 0-10 min, 2\% B; 10-60 min, 2-40\% B; 60-75 $\mathrm{min}, 40 \% \mathrm{~B}$. The column temperature was maintained at $30{ }^{\circ} \mathrm{C}$. The flow rate was $0.8 \mathrm{~mL} / \mathrm{min}$ and the injection volume was $10 \mu \mathrm{L}$. The detection wavelength was set at $270 \mathrm{~nm}$.

\subsubsection{Method Validation}

The HPLC method was validated in terms of linearity, sensitivity, precision, repeatability, stability and accuracy.

The linearity of each analyte was assessed by plotting its calibration curve with different concentrations and the corresponding peak areas. The standard solution of individual analyte was diluted gradually to determine its LOD and LOQ with signal-to-noise ratio of 3:1 and 10:1, respectively.

A GET sample (No. 5) was used to prepare the sample solution for the precision test, in which the solution was analyzed for six times in a day to evaluate the intra-day precision and analyzed on three consecutive days to evaluate the inter-day precision. In addition, the same sample solution was tested at $0,1,2,4,6,9,12,18,24 \mathrm{~h}$ to investigate the stability. In the repeatability test, six GET samples of No. 5 were extracted and analyzed according to the sample preparation procedure and the HPLC method. In these investigations, the relative standard deviation (RSD) was used to evaluate the variations. In the accuracy test, the certain amounts of the six analytes' standards were added to the GET samples (No. 5) with six replicates. Then, these six mixed samples were treated as the above mentioned method. Recovery rate was used as the evaluation index and calculated as follows.

Recovery rate $(\%)=($ Found amount - Known amount $) \times 100 \% /$ Added amount

\subsection{Detection of Antioxidant Activity}

Many researches demonstrated that DPPH assay was performed to test the ability of compounds or extracts from herbal medicines as free radical scavengers or hydrogen donors and to evaluate their antioxidant capacities. The DPPH free radical scavenging rate was determined to assess the antioxidant activity. According to a slightly modified method [43], the sample was evaporated to dryness and dissolved with methanol. Reaction solution was obtained by mixing $0.75 \mathrm{~mL}$ of sample solution (equivalent to GET from $2.5 \mathrm{mg} / \mathrm{mL}$ to $40 \mathrm{mg} / \mathrm{mL}$ in methanol) with $0.75 \mathrm{~mL}$ DPPH solution (75 $\mathrm{\mu g} / \mathrm{mL}$ in methanol). The blank reaction solution was prepared by replacing sample solution with water as the above operation. All the reaction solutions were placed in the dark at room temperature for 40 minutes and their absorbances were measured at wavelength of $517 \mathrm{~nm}$ with an Infinite M200 PRO spectrophotometer (Tecan Austria GmbH, Grödig, Salzburg, Austria). The scavenging percentage was calculated as the following formula:

$$
\text { DPPH scavenging rate }(\%)=\left(1-\mathrm{A} / \mathrm{A}_{0}\right) \times 100 \%
$$

In the formula, $\mathrm{A}$ is defined as the absorbance of the sample reaction and $\mathrm{A}_{0}$ as the absorbance of the blank reaction solution. To evaluate the free radical scavenging ability of each GET sample, a regression equation of sample concentration $(X)$ and scavenging rate $(Y)$ was used to calculate $\mathrm{IC}_{50}$, half maximal inhibitory concentration. The lower $\mathrm{IC}_{50}$ indicated the higher free radical scavenging ability.

\subsection{Cell Culture and Viability Assay}

Primary cultures of HUVEC were performed at $37{ }^{\circ} \mathrm{C}$ under $5 \% \mathrm{CO}_{2}$ for $2-3$ days in $100 \mathrm{~cm}^{2}$ culture dishes with supplemented Endothelial Cell Medium (ECM) containing 5\% FBS, 100 U/mL 
penicillin and $100 \mathrm{U} / \mathrm{mL}$ streptomycin. HUVEC were detached using the trypsin-EDTA solution and then centrifuged for precipitation at $1000 \mathrm{rpm}$ for 5 minutes at room temperature. Before the cell pellets were mixed in complete medium, the supernatant was removed. After the cells were counted by the cell counting plate, they were seeded at the density of $5 \times 10^{4}$ cells $/ \mathrm{mL}$ in a 96-well plate and grew in cell incubator of $5 \% \mathrm{CO}_{2}$ at $37^{\circ} \mathrm{C}$ To evaluate the cell damage repair ability of GET, the cells were washed with phosphate buffered saline (PBS) and the medium was replaced by ECM containing $30 \mu \mathrm{g} / \mathrm{mL}$ high oxidized low density lipoprotein, human (high ox-LDL) for $24 \mathrm{~h}$. After that, the medium was substituted for the sample solution, which was equivalent to $40 \mu \mathrm{g} / \mathrm{mL}$ of GET distributed in ECM for another $24 \mathrm{~h}$. Untreated cells were compared as the model comparison $[44,45]$.

After treatment above, the cell viability was measured by the MTT method. Briefly, MTT was dissolved at a final concentration of $5 \mathrm{mg} / \mathrm{mL}$ in PBS and then added in a 96-well plate located in the cell incubator. MTT was reduced to blue formazan crystals by the metabolically active cells. After $4 \mathrm{~h}$, the formed crystals were dissolved in $0.15 \mathrm{~mL}$ of dimethyl sulfoxide (DMSO) and the absorbance was read at $490 \mathrm{~nm}$. The increasing rate of HUVEC viability was calculated as follows:

Increasing rate $(\%)=\left(\mathrm{A} / \mathrm{A}_{0}-1\right) \times 100 \%$

In the formula, $\mathrm{A}$ is defined as the absorbance of the GET-treated model cell and $\mathrm{A}_{0}$ as the absorbance of the untreated model cell. The higher increasing rate indicated the greater protective effect on HUVEC.

\subsection{Experimental Design for RSM}

RSM with the Box-Benhnken design (BBD)(3-level, 4-factor) was used to optimize the extraction parameters, which would affect active ingredient yields and bioactivity of each GET sample. In this study, experiments were designed with the four independent extraction parameters, including ethanol concentration $\left(X_{1}, \%\right)$, liquid-solid ratio $\left(X_{2}, \mathrm{~mL} / \mathrm{g}\right)$, extraction time $\left(X_{3}\right.$, minute) and soaking time $\left(X_{4}\right.$, hour). For each parameter, the levels were coded as $-1,0,1$ with details in Table 6 . The dependent variables were the contents of the six gastrodin-type components $\left(Y_{1}\right), \mathrm{IC}_{50}$ of DPPH scavenging rate $\left(Y_{2}\right)$ and increasing rate of HUVEC viability $\left(Y_{3}\right)$. In order to eliminate the effects of various dimensions and units, the three dependent variables should be standardized as the following formulas:

$$
\begin{aligned}
& Y_{1}=\left[\left(\mathrm{S}_{\mathrm{i}(\mathrm{GD})}-\mathrm{S}_{\min (\mathrm{GD})}\right) /\left(\mathrm{S}_{\max (\mathrm{GD})}-\mathrm{S}_{\min (\mathrm{GD})}\right)+\left(\mathrm{S}_{\mathrm{i}(\mathrm{GG})}-\mathrm{S}_{\min (\mathrm{GG})}\right) /\left(\mathrm{S}_{\max (\mathrm{GG})}-\mathrm{S}_{\min (\mathrm{GG})}\right)\right. \\
& +\left(\mathrm{S}_{\mathrm{i}(\mathrm{PA})}-\mathrm{S}_{\min (\mathrm{PA})}\right) /\left(\mathrm{S}_{\max (\mathrm{PA})}-\mathrm{S}_{\min (\mathrm{PA})}\right)+\left(\mathrm{S}_{\mathrm{i}(\mathrm{PB})}-\mathrm{S}_{\min (\mathrm{PB})}\right) /\left(\mathrm{S}_{\max (\mathrm{PB})}-\mathrm{S}_{\min (\mathrm{PB})}\right)+\left(\mathrm{S}_{\mathrm{i}(\mathrm{PC})}-\right. \\
& \left.\left.\mathrm{S}_{\min (\mathrm{PC})}\right) /\left(\mathrm{S}_{\max (\mathrm{PC})}-\mathrm{S}_{\min (\mathrm{PC})}\right)+\left(\mathrm{S}_{\mathrm{i}(\mathrm{PE})}-\mathrm{S}_{\min (\mathrm{PE})}\right) /\left(\mathrm{S}_{\max (\mathrm{PE})}-\mathrm{S}_{\min (\mathrm{PE})}\right)\right] / 6 \\
& \quad Y_{2}=\left(\mathrm{IC}_{50, \mathrm{i}}-\mathrm{IC}_{50, \min }\right) /\left(\mathrm{IC}_{50, \max }-\mathrm{IC}_{50, \min }\right) \\
& \quad Y_{3}=\left(\mathrm{S}_{\mathrm{MTT}, \mathrm{i}}-\mathrm{S}_{\mathrm{MTT}, \min }\right) /\left(\mathrm{S}_{\mathrm{MTT}, \max }-\mathrm{S}_{\mathrm{MTT}, \min }\right)
\end{aligned}
$$

In the formulas, $\mathrm{S}_{\mathrm{i}(\mathrm{GD})}, \mathrm{S}_{\min (\mathrm{GD})}$ and $\mathrm{S}_{\min (\mathrm{GD})}$ represented a certain content, the minimum content and the maximum content of GD in 29 samples, respectively. The other five gastrodin-type components were expressed in the same way. $\mathrm{S}_{\mathrm{i}(\mathrm{MTT})}, \mathrm{S}_{\min (\mathrm{MTT})}$ and $\mathrm{S}_{\max (\mathrm{MTT})}$ were a certain value, the minimum value and the maximum value of cell viability increasing rate while $\mathrm{IC}_{50, \mathrm{i}}, \mathrm{IC}_{50 \text {, min }}$ and $\mathrm{IC}_{50 \text {,max }}$ were a certain value, the minimum value and the maximum value of $\mathrm{IC}_{50}$ in 29 samples. The three dependent variables were separately calculated. $\mathrm{IC}_{50}$ was a "less-better" variable while the other two were "more-better" ones. So, the comprehensive dependent variable was recorded as $Y$ and calculated as follows: $Y=Y_{1}-Y_{2}+Y_{3}$.

\subsection{Data Analysis}

Design Expert software (version 5.0.8) was used to conduct the experimental design and data analysis. To predict the response variables, a model was applied as the following formula:

$$
\begin{aligned}
& Y=b_{0}-b_{1} X_{1}+b_{2} X_{2}+b_{3} X_{3}+b_{4} X_{4}-b_{1} b_{2} X_{1} X_{2}+b_{1} b_{3} X_{1} X_{3}+b_{1} b_{4} X_{1} X_{4}-b_{2} b_{3} X_{2} X_{3}+b_{2} b_{4} X_{2} X_{4} \\
& +b_{3} b_{4} X_{3} X_{4}-b_{1}{ }^{2} X_{1}^{2}-b_{2}{ }^{2} X_{2}^{2}-b_{3}^{2} X_{3}^{2}-b_{4}^{2} X_{4}^{2}
\end{aligned}
$$


In the formula, $Y$ was the predicted dependent variable; $X_{1}, X_{2}, X_{3}, X_{4}$ were the predicted independent variable; $b_{0}$ was a constant that fixed the response of the experiment; $b_{1}, b_{2}, b_{3}$ and $b_{4}$ were the regression coefficients on the linear effect terms; $b_{1} b_{2}, b_{1} b_{3}, b_{1} b_{4}, b_{2} b_{3}, b_{2} b_{4}$ and $b_{3} b_{4}$ were those on the interaction effect terms; $\mathrm{b}_{1}{ }^{2}, \mathrm{~b}_{2}{ }^{2}, \mathrm{~b}_{3}{ }^{2}$ and $\mathrm{b}_{4}{ }^{2}$ were those on the quadratic effect terms.

To calculate the statistical significance of the model, analysis of variance (ANOVA) and response surface analysis were selected for testing.

\section{Conclusions}

The conventional extraction optimization usually paid attention to the contents of some phytochemicals in herbal medicines. However, as the most potential indicator of quality evaluation, bioactivity has not been involved. In this study, we selected anti-oxidation ( $\mathrm{IC}_{50}$ of DPPH radical scavenging) and protection of HUVEC (damage repair rate by MTT) as the bioactivities, which were related to many pharmacological activities of GET. With the integrated bioactivity index and quantitative index, the extraction conditions were optimized and a quadratic polynomial model was obtained for the extraction of the gastrodin-type components (GD, GG, PA, PB, PC, PE) in GET by the aid of BBD and RSM. Four main factors were employed as independent variables in the model, including ethanol concentration, liquid-solid ratio, soaking time and extraction time. Validated by the confirmatory experiments, the optimum extraction conditions were listed as follows: ethanol concentration of $41 \%$, liquid-solid ratio of $28.58 \mathrm{~mL} / \mathrm{g}$, soaking time of $23.91 \mathrm{~h}$ and extraction time of $46.60 \mathrm{~min}$.

As we know, the bioactive components are the material basis of the efficacy of TCMs. So, in most conditions, the contents of the major components were used for quality evaluation of TCMs and employed as the important indicators for extraction optimization of TCMs. However, just the contents of chemical components could not comprehensively reflect the quality of TCMs. The efficacy itself is actually the straight-forward index for quality evaluation. In terms of operation, cost and time, in vitro bioactivity investigation is a better choice than in vivo. In this study, we integrated the phytochemical yields and in vitro bioactivities of GET for extraction optimization. The further objective was to explore a novel strategy for quality evaluation and even application to other related research aspects of other TCMs.

Author Contributions: M.H. is the first author on this work. M.S. is the corresponding authors. All authors contributed to the experiments and approved the final manuscript. Conceptualization, M.S., A.D., Q.W., L.Z., W.Y., H.Y. and S.Y.; Methodology, M.S. and H.Y.; Software, W.Y. and M.H.; Validation, M.S., M.H. and S.Y.; Formal Analysis, M.H., Y.F. and Y.J.; Data curation, M.H. and Y.J.; Writing-Original Draft Preparation, M.H. and Y.F.; Writing-Review \& Editing, M.S., L.Z. and A.D.; Supervision, M.S.

Funding: This research was financially supported by China Agriculture Research System (CARS-21), Ministry of Finance Central Level of the Special (No.2060302), Priority Academic Program Development of Jiangsu Higher Education Institutions (PAPD-2014), Top-notch Academic Programs Project of Jiangsu Higher Education Institutions (TAPP-PPZY2015A070) and the Key Research Project of Jiangsu Collaborative Innovation Center of Chinese Medicinal Resources Industrialization (ZDXM-1-3).

Conflicts of Interest: The authors have declared no conflict of interest.

\section{References}

1. Lee, D.K.; Lim, D.K.; Um, J.A.; Lim, C.J.; Hong, J.Y.; Yoon, Y.A.; Ryu, Y.; Kim, H.J.; Cho, H.J.; Park, J.H.; et al. Evaluation of four different analytical tools to determine the regional origin of Gastrodia elata and Rehmannia glutinosa on the basis of metabolomics study. Molecules 2014, 19, 6294-6308. [CrossRef]

2. The National Pharmacopoeia Commission of P.R. China. Pharmacopoeia of the People's Republic of China; China Medicine Science Technology Press: Beijing, China, 2015; pp. 200-201.

3. Song, E.; Chung, H.; Shim, E.; Jeong, J.K.; Han, B.K.; Choi, H.J.; Hwang, J. Gastrodia elata Blume extract modulates antioxidant activity and ultraviolet A-irradiated skin aging in human dermal fibroblast cells. J. Med. Food 2016, 19, 1057-1064. [CrossRef] [PubMed] 
4. Ahn, E.K.; Jeon, H.J.; Lim, E.J.; Jung, H.J.; Park, E.H. Anti-inflammatory and anti-angiogenic activities of Gastrodia elata Blume. J. Ethnopharmacol. 2007, 110, 476-482. [CrossRef] [PubMed]

5. Huang, G.B.; Zhao, T.; Muna, S.S.; Jin, H.M.; Park, J.I.; Jo, K.S.; Lee, B.H.; Chae, S.W.; Kim, S.Y.; Park, S.H.; et al. Therapeutic potential of Gastrodia elata Blume for the treatment of Alzheimer's disease. Neural Regen. Res. 2013, 8, 1061-1070. [PubMed]

6. Lin, Y.E.; Lin, S.H.; Chen, W.C.; Ho, C.T.; Lai, Y.S.; Panyod, S.; Lai, Y.S.; Ho, C.T.; Sheen, L.Y. Antidepressant-like effects of water extract of Gastrodia elata blume in rats exposed to unpredictable chronic mild stress via modulation of monoamine regulatory pathways. J. Ethnopharmacol. 2016, 187, 57-65. [CrossRef] [PubMed]

7. Kumar, H.; Kim, I.S.; More, S.V.; Kim, B.W.; Bahk, Y.Y.; Choi, D.K. Gastrodin protects apoptotic dopaminergic neurons in a toxin-induced Parkinson's disease model. Evid.-Based Complment. Altern. 2013. [CrossRef] [PubMed]

8. Jung, J.W.; Yoon, B.H.; Oh, H.R.; Ahn, J.H.; Kim, S.Y.; Park, S.Y.; Ryu, J.F. Anxiolytic-Like effects of Gastrodia elata and its phenolic constituents in mice. Biol. Pharm. Bull. 2006, 29, 261-265. [CrossRef]

9. Zhang, Y.; Li, M.; Kang, R.X.; Shi, J.G.; Liu, G.T.; Zhang, J.J. NHBA isolated from Gastrodia elata exerts sedative and hypnotic effects in sodium pentobarbital-treated mice. Pharmacol. Biochem. Behav. 2012, 102, 450-457. [CrossRef]

10. Zhao, Y.; Kang, Z.J.; Zhou, X.; Yang, S.L. An edible medicinal plant-Gastrodia elata Bl. J. Guizhou Norm. Univ. 2013, 31, 9-12.

11. Kang, C.; Lai, C.J.; Zhao, D.; Zhou, T.; Liu, D.H.; Lv, C.; Wang, S.; Kang, L.; Yang, J.; Zhan, Z.L.; et al. A practical protocol for comprehensive evaluation of sulfur-fumigation of Gastrodia Rhizoma using metabolome and health risk assessment analysis. J. Hazard. Mater. 2017, 340, 221-230. [CrossRef]

12. Chen, W.C.; Lai, Y.S.; Lin, S.H.; Lu, K.H.; Lin, Y.E.; Panyod, S.; Ho, C.T.; Sheen, L.Y. Anti-depressant effects of Gastrodia elata Blume and its compounds gastrodin and 4-hydroxybenzyl alcohol, via the monoaminergic system and neuronal cytoskeletal remodeling. J. Ethnopharmacol. 2016, 182, 190-199. [CrossRef] [PubMed]

13. Jiang, G.L.; Hu, Y.Q.; Liu, L.L.; Cai, J.L.; Peng, C.; Li, Q.L. Gastrodin protects against MPP+-induced oxidative stress by up regulates heme oxygenase-1 expression through p38 MAPK/Nrf2 pathway in human dopaminergic cells. Neurochem. Int. 2014, 75, 79-88. [CrossRef] [PubMed]

14. Luo, L.; Kim, S.W.; Lee, H.K.; Kim, I.D.; Lee, H.; Lee, J.K. Anti-oxidative effects of 4-hydroxybenzyl alcohol in astrocytes confer protective effects in autocrine and paracrine manners. PLoS ONE 2017, 12. [CrossRef] [PubMed]

15. Haddadi, R.; Poursina, M.; Zeraati, F.; Nadi, F. Gastrodin microinjection suppresses 6-OHDA-induced motor impairments in parkinsonian rats: Insights into oxidative balance and microglial activation in SNc. Inflammopharmacology 2018, 26, 1305-1316. [CrossRef] [PubMed]

16. Liu, Y.; Ran, R.; Huang, G.L. Study on the best initial processing technology of Gastrodia elata. Pharm. Chem. J. 2018, 52, 224-230. [CrossRef]

17. Zhang, M.H.; Fan, L.; Gao, T.T. A comparison of extraction techniques on gastrodin from Gastrodia elata by response surface methodology and orthogonal design. J. Gansu Agric. Univ. 2014, 49, 60-65.

18. Xu, D.Q.; Zhou, J.J.; Liu, Y.H. Research the extraction and detection method of gastrodin content in Gastrodia elata. J. Chin. Med. Mater. 2012, 35, 1799-1804.

19. Yue, L.; Zhang, F.; Wang, Z.X. Study on ultrasonic extraction of gastrodin from Gastrodia elata Bl. Sep. Sci. Technol. 2010, 45, 832-838. [CrossRef]

20. Shan, M.Q.; Zhang, L.; Yu, S.; Qian, Y.; Wang, J.Y.; Ding, A.W. Simultaneous determination of eight active components in Gastrodiae Rhizoma by HPLC-MS. Chin. Tradit. Herbal Drugs 2015, 46, 2087-2091.

21. Ku, Y.R.; Liu, Y.C.; Hau, J.P.; Wen, K.C.; Lin, J.H.; Huang, W.F. Determination of parishin, parishins B and C in Gastrodiae Rhizoma by HPLC. J. Food Drug Anal. 1995, 3, 287-293.

22. Liu, Z.H.; Wang, W.P.; Feng, N.; Wang, L.; Shi, J.G.; Wang, X.L. Parishin C's prevention of A $\beta(1-42)$-induced inhibition of long-term potentiation is related to NMDA receptors. Acta Pharm. Sin. B 2016, 6, 189-197. [CrossRef] [PubMed]

23. Lin, Y.F.; Sun, Y.J.; Weng, Y.F.; Matsuura, A.; Xiang, L.; Qi, J.H. Parishin from Gastrodia elata extends the lifespan of yeast via regulation of Sir2/Uth1/TOR signaling pathway. Oxid. Med. Cell. Longev. 2016. [CrossRef] [PubMed] 
24. Shin, E.J.; Whang, W.K.; Kim, S.; Bach, J.H.; Kim, J.M.; Nguyen, X.K.T.; Nguyen, T.T.L.; Jung, B.D.; Yamada, K.; Nabeshima, T.; et al. Parishin C attenuates phencyclidine-induced schizophrenia-like psychosis in mice: Involvements of 5-HT1A receptor. J. Pharmacol. Sci. 2010, 113, 404-408. [CrossRef] [PubMed]

25. Berek, L.; Szabo, D.; Petri, I.B.; Shoyama, Y.; Lin, Y.H.; Molnar, J. Effects of naturally occurring glucosides, solasodine glucosides, ginsenosides and parishinderivatives on multidrug resistance of lymphoma cells and leukocyte functions. In Vivo 2001, 15, 151-156. [PubMed]

26. Tang, C.L.; Wang, L.; Liu, X.X.; Cheng, M.C.; Qu, Y.; Xiao, H.B. Comparative pharmacokinetics of gastrodin in rats after intragastric administration of free gastrodin, parishin and Gastrodia elata extract. J. Ethnopharmacol. 2015, 176, 49-54. [CrossRef] [PubMed]

27. Tang, C.L.; Wang, L.; Li, J.J.; Liu, X.X.; Cheng, M.C.; Xiao, H.B. Analysis of the metabolic profile of parishin by ultra-performance liquid chromatography/quadrupole-time of flight mass spectrometry. Biomed. Chromatogr. 2015, 29, 1913-1920. [CrossRef] [PubMed]

28. Lee, Y.J.; Hwang, S.M.; Kang, D.G.; Kim, J.S.; Lee, H.S. Effect of Gastrodia elata on tumor necrosis factor-alpha-induced matrix metalloproteinase activity in endothelial cells. J. Nat. Med. 2009, 63, 463-467. [CrossRef]

29. Hwang, S.M.; Lee, Y.J.; Kang, D.G.; Lee, H.S. Anti-Inflammatory effect of Gastrodia elata rhizome in human umbilical vein endothelial cells. Am. J. Chin. Med. 2009, 37, 395-406. [CrossRef]

30. Seok, P.R.; Kim, J.H.; Kwon, H.R.; Heo, J.S.; Choi, J.R.; Shin, J.H. Protective effects of Gastrodia elata Blume on acetaminophen-induced liver and kidney toxicity in rats. Food Sci. Biotechnol. 2018, 27, 1445-1454. [CrossRef]

31. Chen, L.; Zhang, Y.P.; Jin, L.X. Preparation, characterization and anti-ageing activity of Gastrodia elata blume polysaccharide. Acta Aliment. 2018, 47, 210-219. [CrossRef]

32. Shi, A.H.; Xiang, J.M.; He, F.Y.; Zhu, Y.P.; Zhu, G.B.; Lin, Y.H.; Zhou, N.N. The phenolic components of Gastrodia elata improve prognosis in rats after cerebral ischemia/reperfusion by enhancing the endogenous antioxidant mechanisms. Oxid. Med. Cell. Longev. 2018. [CrossRef] [PubMed]

33. Fang, H.; Zhang, W.J.; Zhang, J.C.; Yang, M.; Zhang, F.X.; Zhang, J.P. Anti-hypertensive effect of Gastrodia elata Bl leaf extract in rats. Trop. J. Pharm. Res. 2017, 16, 1887-1891. [CrossRef]

34. Huang, J.Y.; Yuan, Y.H.; Yan, J.Q.; Wang, Y.N.; Chu, S.F.; Zhu, C.G.; Guo, Q.L.; Shi, J.G.; Chen, N.H. 20C, a bibenzyl compound isolated from Gastrodia elata, protects PC12 cells against rotenone-induced apoptosis via activation of the Nrf2/ARE/HO-1 signaling pathway. Acta Pharmacol. Sin. 2016, 37, 731-740. [CrossRef] [PubMed]

35. Kim, I.S.; Choi, D.K.; Jung, H.J. Neuroprotective Effects of vanillyl alcohol in Gastrodia elata Blume through suppression of oxidative stress and anti-apoptotic activity in toxin-induced dopaminergic MN9D cells. Molecules 2011, 16, 5349-5361. [CrossRef] [PubMed]

36. Yu, S.J.; Kim, J.R.; Lee, C.K.; Han, J.E.; Lee, J.H.; Kim, H.S.; Hong, J.H.; Kang, S.G. Gastrodia elata blume and an active component, p-hydroxybenzyl alcohol reduce focal ischemic brain injury through antioxidant related gene expressions. Biol. Pharm. Bull. 2005, 28, 1016-1020. [CrossRef] [PubMed]

37. Granato, D.; Grevink, R.; Zielinski, A.A.F.; Nunes, D.S.; van Ruth, S.M. Analytical strategy coupled with Response Surface Methodology to maximize the extraction of antioxidants from ternary mixtures of Green, Yellow and Red Teas (Camellia sinensis var. sinensis). J. Agric. Food Chem. 2014, 62, 10283-10296. [CrossRef] [PubMed]

38. Pinho, C.; Melo, A.; Mansilha, C.; Ferreira, I.M.P.L.V.O. Optimization of conditions for anthocyanin hydrolysis from red wine using Response Surface Methodology (RSM). J. Agric. Food Chem. 2011, 59, 50-55. [CrossRef] [PubMed]

39. Sharif, I.; Adewale, P.; Dalli, S.S.; Rakshit, S. Microwave pretreatment and optimization of osmotic dehydration of wild blueberries using response surface methodology. Food Chem. 2018, 269, 300-310. [CrossRef] [PubMed]

40. Masghati, S.; Ghoreishi, S.M. Supercritical $\mathrm{CO}_{2}$ extraction of cinnamaldehyde and eugenol from cinnamon bark: Optimization of operating conditions via response surface methodology. J. Supercrit. Fluid 2018, 140, 62-71. [CrossRef]

41. Yoon, J.H.; Kim, J.H.; Ham, S.S.; Gang, B.Y.; Lee, S.H.; Choi, G.; Kim, Y.S.; Lee, G.; Ju, Y.S. Optimal processing conditions of Boswellia carteri Birdw. using Response Surface Methodology. Phamacogn. Mag. 2018, 14, 235-241. 
42. Ha, W.R.; Park, J.H.; Kim, J.H. Optimization for decocting later of Menthae Herba in Eungyo-San, a herbal formula, using Response Surface Methodology with gas chromatography/mass spectrometry. Phamacogn. Mag. 2018, 14, 17-21.

43. Kumarasamy, Y.; Byres, M.; Cox, P.J.; Jaspars, M.; Nahar, L.; Sarker, S.D. Screening seeds of some Scottish plants for free radical scavenging activity. Phytother. Res. 2007, 21, 615-621. [CrossRef] [PubMed]

44. Guo, H.L.; Chen, Y.L.; Liao, L.Z.; Wu, W.K. Resveratrol protects HUVECs from oxidized-LDL induced oxidative damage by autophagy upregulation via the AMPK/SIRT1 pathway. Cardiovasc. Drugs Ther. 2013, 27, 189-198. [CrossRef] [PubMed]

45. Shen, X.C.; Tao, L.; Li, W.K.; Zhang, Y.Y.; Luo, H.; Xia, Y.Y. Evidence-based antioxidant activity of the essential oil from Fructus A. zerumbet on cultured human umbilical vein endothelial cells' injury induced by ox-LDL. BMC Complemt. Altern. Med. 2012, 12. [CrossRef] [PubMed]

Sample Availability: Not available.

(C) 2019 by the authors. Licensee MDPI, Basel, Switzerland. This article is an open access article distributed under the terms and conditions of the Creative Commons Attribution (CC BY) license (http://creativecommons.org/licenses/by/4.0/). 